\title{
Optimization of InGaAs/InGaAsP MQW mqw semiconductor amplifiers
}

\author{
Jepsen, Kim Stokholm; Mikkelsen, Benny; Yamamchi, M.; Stubkjær, Kristian
}

Published in:

Proceedings of the 13th IEEE International Semiconductor Laser Conference

Publication date:

1992

Document Version

Publisher's PDF, also known as Version of record

Link back to DTU Orbit

Citation (APA):

Jepsen, K. S., Mikkelsen, B., Yamamchi, M., \& Stubkjær, K. (1992). Optimization of InGaAs/InGaAsP MQW mqw semiconductor amplifiers. In Proceedings of the 13th IEEE International Semiconductor Laser Conference (pp. 64-65). IEEE.

\section{General rights}

Copyright and moral rights for the publications made accessible in the public portal are retained by the authors and/or other copyright owners and it is a condition of accessing publications that users recognise and abide by the legal requirements associated with these rights.

- Users may download and print one copy of any publication from the public portal for the purpose of private study or research.

- You may not further distribute the material or use it for any profit-making activity or commercial gain

- You may freely distribute the URL identifying the publication in the public portal

If you believe that this document breaches copyright please contact us providing details, and we will remove access to the work immediately and investigate your claim. 


\title{
Optimization of InGaAs/InGaAsP MQW Semiconductor Amplifiers
}

\author{
K. S. Jepsen, B. Mikkelsen, M. Yamaguchi", K. E. Stubkjaer \\ Center for Broadband Telecommunications, Technical University of Denmark, DK-2800 \\ *NEC Research Laboratories, Tsukuba-si, 305 Japan
}

Semiconductor optical amplifiers (SOAs) based on quantum-wells $(\mathrm{QW})$ are reported to have a low noise figure [1] and a large gain bandwidth [2] compared to bulk SOAs. These features make the QW SOA an attractive component for use as a pre-amplifier in future OEICs. In this paper the optimization of QW-structures for a low noise figure and a high gain is considered. Contrary to previous work [3], our model suggests that the noise figure does not depend critically on the number of wells. In addition, the predictions are compared to measurements of the noise figure and gain for a multiple quantum-well (MQW) amplifier.

The gain is calculated using the $\mathbf{k} \cdot \mathbf{p}$-approximation, taking into account both the conduction band/heavy hole band and the conduction band/ light hole band transitions. The noise figure is found from the formula [2],[4]:

$$
F=2 \frac{\Gamma \alpha_{e}}{\Gamma g-\alpha_{l o s s}} \equiv 2 \gamma_{s p} \frac{g}{\left(g-\left(\alpha_{a}-\alpha_{b}\right)\right)-\alpha_{b} / \Gamma}
$$

where $\Gamma$ is the optical confinement factor, $\alpha_{\mathrm{e}}$ is the rate of stimulated emission of photons into the optical mode divided by the group velocity of light, $g$ the gain, $\gamma_{s p} \equiv \alpha_{e} / g$ defines the population inversion parameter, $\alpha_{a}$ is the loss in the active layers and $\alpha_{b}$ the loss in the barrier layers. Although small, the barrier loss has substantial effect on the noise figure, due to the little confinement factor. The increase in junction temperature due to the injection current has been included in the model.

In Fig. 1 the gain and corresponding noise figure are shown for 500 and $800 \mu \mathrm{m}$ long 4-well MQW amplifiers as a function of injected current with the well width as a parameter. The gain and the noise figure are optimized for a well width of approximately $40 \AA$ as a result of several effects [3]. The increase of the confinement factor and the approach of the heavy-hole and light-hole confined states to each other act to increase the gain with the well width. On the other hand the increase in the density of states with well width lowers the Fermi-levels, thereby reducing the gain. Experimental results for the single-pass gain and noise figure at the gain peak (TE-polarization) are also shown in Fig. 1 for comprarison. The agreement between the calculated and the experimental results is acceptable and taken as a verification of the model.

The above results show an optimum well wid:h of $40 \AA$. In practice it is convenient to use In $\mathrm{CraAs}$ and InGaAsP lattice matched to InP. This implies a well width around $80 \AA$ for a wavelength of $1.5 \mu \mathrm{m}$ The model is therefore used to evaluate the noise figure dependence on the number of wells, $\mathrm{N}_{\mathrm{Q}}$, for this well width. From the equation it is clear that the noise figure is minir.ized when the confinement factor is large, as ir. the case of many wells. However, if the length, $L$, of the amplifier is kept constant the carrier density will drop due to the larger active volume. To analyze this, two cases are considered, namely 1) constant amplifier length and bias current as in [3], and 2) constant active volume and gain. In the first case the noise figure increases with the number of wells, because the carrier density drops. This is shown in Fig. 2 (open circles) for an $800 \mu \mathrm{m}$ long amplifier. The bias current is $150 \mathrm{~mA}$. Despite the decreasing carrier density the gain increases with the number of wells as shown in Table 1. This is due to the increase in the confinement factor. Thus, a trade-off exists between noise figure and gain. In the second case the length is reduced as to keep the active volume constant. The bias current is adjusted to give a single-pass gain of $20 \mathrm{~dB}$. As seen in Fig. 2 (closed triangles), the noise figure decreases slightly with the number of wells berause while the carrier density remains constan:, the 
influence of the barrier losses are minimized. The benefit of using many parallel wells is reduced by higher operating temperatures as seen in the table where a detailed list of parameters is given. As the dependence of the noise figure on the number of wells is negligible, the optimum well number is 4-6 considering realistic lengths and low operating temperatures.
[1] T. Saitoh et. al., IEEE Photon. Technol. Lett. vol. 2, pp. 794-796, Nov. 1990.

[2] K. S. Jepsen et al., accepted for publ. in IEEE Photon. Technol. Lett., June 1992.

[3] P. J. Stevens, T. Mukai, IEEE J. Quantum Electron., vol. 26, pp.1910-1917, 1990.

[4] K. Komori et al., IEEE Photon. Technol. Lett., vol. 3, pp.39-41, 1991.
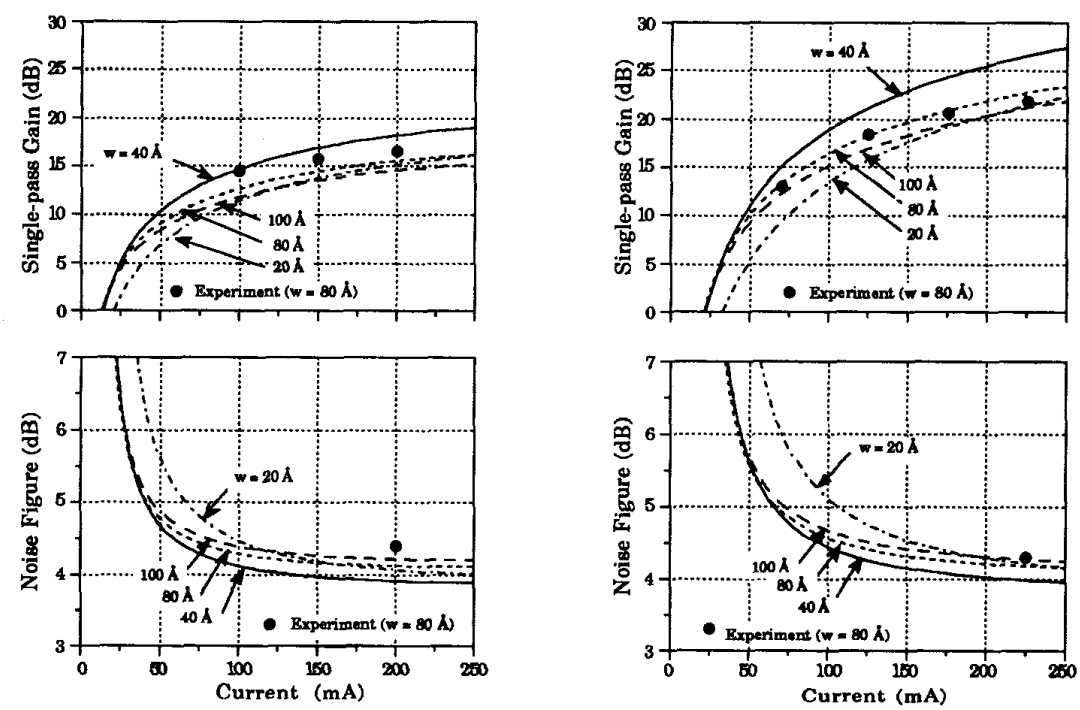

Fig. 1 Single-pass gain and noise figure vs. current density for 4-well amplifiers with the well width as parameter. The amplifier lengths $L$ are $\mathbf{5 0 0}$ and $800 \mu \mathrm{m}$, respectively.

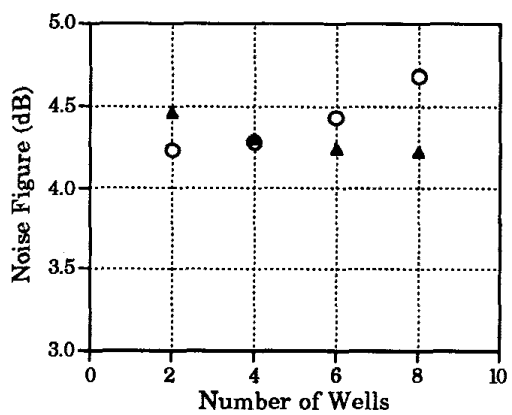

Fig. 2 Noise figure vs. number of wells. Open circles are for $\mathrm{L}=800 \mu \mathrm{m}$, bias constant at $150 \mathrm{~mA}$. Closed triangles are for $\mathrm{G}=20 \mathrm{~dB}$ with length adjusted to give constant active volume. Well-width is $80 \AA$.
Table 1 Noise figure and parameters corresponding to the two cases considered in Fig. 2.

\begin{tabular}{|c||ccc||cccc|}
\hline$N_{Q}$ & \multicolumn{3}{c||}{$\mathrm{L}=800 \mu \mathrm{m}}$, & \multicolumn{4}{c|}{ Gain $=20 \mathrm{~dB}$} \\
& \multicolumn{3}{|c|}{ Bias $=150 \mathrm{~mA}$} & & & & \\
\hline & $\mathrm{NF}$ & Gain & Temp & $\mathrm{NF}$ & $\mathrm{L}$ & Bias & Temp \\
& $\mathrm{dB}$ & $\mathrm{dB}$ & $\mathrm{K}$ & $\mathrm{dB}$ & $\mu \mathrm{m}$ & $\mathrm{mA}$ & $\mathrm{K}$ \\
\hline 2 & 4.23 & 12.6 & 293 & 4.46 & 1600 & 168 & 297 \\
4 & 4.28 & 20.2 & 293 & 4.30 & 800 & 155 & 302 \\
6 & 4.43 & 26.0 & 293 & 4.25 & 533 & 158 & 310 \\
8 & 4.68 & 29.1 & 293 & 4.22 & 400 & 176 & 322 \\
\hline
\end{tabular}

